\title{
Modeling and Evaluation of Milling Cutter Processing Capacity Based on Relational Algebra
}

\author{
Weiwei $\mathrm{Ma}^{1, \mathrm{a}}$, Yan $\mathrm{CaO}^{2, \mathrm{~b}}$, Leijie $\mathrm{Fu}^{3}, \mathrm{Yu} \mathrm{Bai}^{4}$ \\ 1,2,3,4 The Institute of Mechanical and Electrical Engineer, Xi'an Technological University, Xi'an \\ 710032 \\ a944345912@qq.com, bjantonyz@163.com
}

Keywords: Milling cutter processing capacity; Fuzzy evaluation; Analytic hierarchy process.

\begin{abstract}
In this paper, facing the problem of tool selection in the machining process, an evaluation model of machining capacity of milling cutter, which is based on the method of relational algebra, is established. First, affecting processing capability factors are integrated by modeling. Second, these factors are quantized through the fuzzy evaluation method, and the data from quantitative processing are weight compared. Final, the comparative analysis of the models commonly used in the evaluation the processing capacity was conducted, which provided the corresponding reference for the model subsequent selection in the processing capacity evaluation. This method has a certainly significance for the choice of tool during machining in the process.
\end{abstract}

\section{Introduction}

Tool is the key factor affecting the efficiency of manufacturing industry, and the correct choice of cutting tool has a significant effect on the efficiency of manufacturing industry. The criterion to select tool is vary widely, so it is very significant and valuable for the manufacturing industry to find a unified measure to evaluate the processing capacity of the cutter. The research neglected the influence of the typical structural characteristics on the tool performance, and the lack of an effective comprehensive evaluation method to evaluate the tool processing capacity in the past, thus seeking an effective method for further evaluation of the tool processing ability is extremely important. In the 1990s, Song Yu yin ${ }^{[1]}$ established a manufacturing resource capability model based on STEP, they evaluate the manufacturability of parts which based on manufacturing resource and knowledge, the feedback information of part design is presented thus guiding the product design. Wang Juan ${ }^{[2]}$ put forward an evaluation system of machining capability of CNC machine tools from the factors of general processing capability and special processing capability, and then the evaluation model of machining capability matching was established by applying fuzzy comprehensive method. After more than ten years of research, comprehensive evaluation methods and theory has been greatly improved, but there is still a comprehensive evaluation of the problem is not a good method to determine the weight of indicators. According to the above literature to describe the processing capacity and processing capacity of some related methods, a method based on fuzzy evaluation and analytic hierarchy process (AHP) is proposed, and on the basis of this method using relational algebra to the influence factors of affecting milling cutter machining capacity extension analysis.

\section{Formal Modeling of Machining Capacity of Milling Cutter}

Define Processing Capabilities. Modeling and evaluation of tool processing capability can provide basic data support for tool service, virtual access, and searching, matching and management of machining capabilities in service-oriented manufacturing and cloud manufacturing. So understanding the processing capacity of the tool and the ability to evaluate the processing is necessary. Xiao Ying ying [3] and others according to the application demand of manufacturing capability service (MCs) in cloud manufacturing system, MCs' formalization description method was focused on. Zhu Qi qi [4] and so on using the method of relational algebra and set theory at the problem of processing capacity modeling in the process of service system and virtualization, the 
processing capability and related concepts are defined according to the function, performance and quality of the machining system. Based on the description of the above description of the ability to define the milling cutter, its processing capacity can be described as: processing cutter is operating activities on the characteristics of milling cutter and parts, which can play a function of milling processing to complete the feature in the performance constraint range, process and ability to achieve a certain technical performance. With the definition of the milling capacity of the milling cutter, there is a corresponding definition and standard for the evaluation of the processing ability of the tool.

\section{Modeling of Milling Cutter Processing Capacity.}

(1) Establishment of the model tree

The evaluation of machining ability of tool is a multi-factor and multi-level comprehensive evaluation problem. Traditional tool evaluation often emphasizes the quality of machining parts, processing time and processing cost, while ignoring some performance of the tool itself and some factors affecting the process, which is not perfect for the evaluation of the tool. This paper from three aspects of precision machining parts, the tool itself and some influence factors during the machining process as a first-level indicators, and continue to break down the first-level indicators, established a model tree comprehensive evaluation system of milling cutters, as shown in fig 1.

(2) Using the relational algebra method to describe the algebraic relational expression of milling capacity model. Formula is as follows.

Tool Processing Capacity $=\{$ Processing Accuracy,Bas-factors, Out-factors $\}$

During the above formula, the accuracy of machined parts is the Processing Accuracy; Bas-factors represents some factors Tool own behalf; Out-factors represents the Some Influencing Factors of Cutting Tool in Processing. The relationship of them is shown in Fig. 1

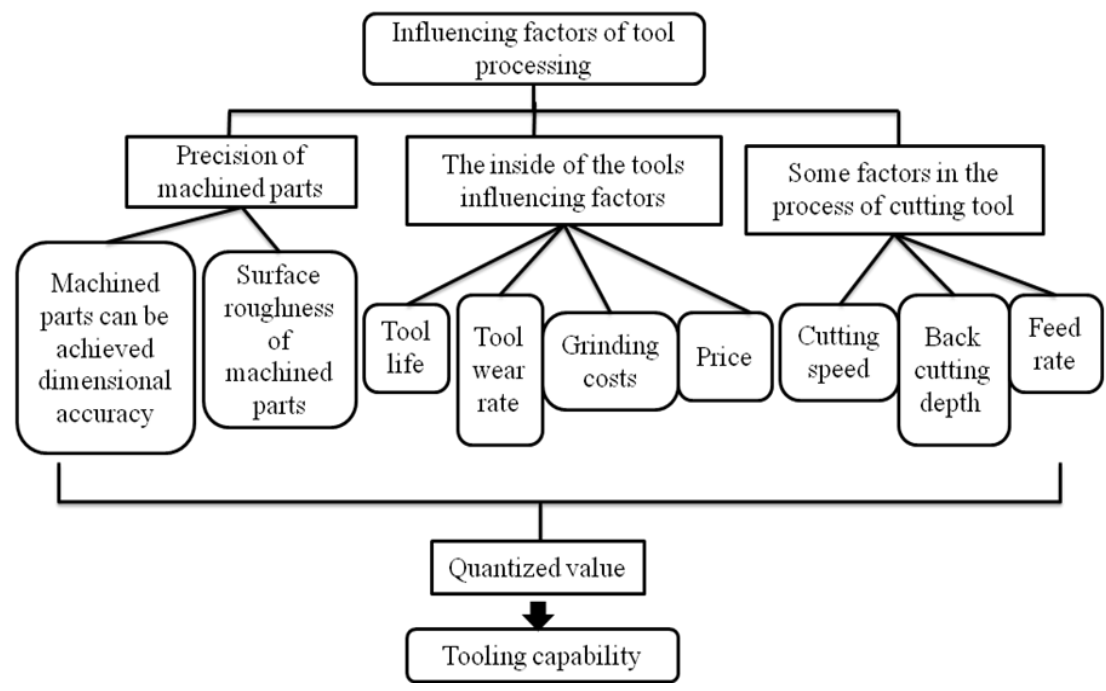

Figure 1. Model Tree of Milling Cutter's Processing Ability

Processing Accuracies $=\{\mathrm{DA}, \mathrm{RL}\}$;

Bas-factors $=\{\mathrm{WR}, \mathrm{CL}, \mathrm{GC}, \mathrm{TP}\}$;

Out-factors $=\{\mathrm{CS}, \mathrm{TB}, \mathrm{FR}\}$.

The relationship representation therein is described below.

AA - Represents the Machined parts can be achieved dimensional accuracy $(\mathrm{L} / \mu \mathrm{m})$;

$\mathrm{RL} \longrightarrow$ Represents the Surface roughness of machined parts $(\mathrm{Ra} / \mu \mathrm{m})$;

WR-Represents the Tool wear rate $(\%)$;

$\mathrm{CL}-$ Represents the Tool life (h);

GC- Represents the Grinding costs (yuan);

$\mathrm{TP}-$ Represents the Price (yuan/each); 
$\mathrm{CS}-$ Represents the Cutting speed ( $\mathrm{r} / \mathrm{min})$;

$\mathrm{TB}-$ Represents the Back cutting depth (mm);

FR—-Represents the Feed rate $(\mathrm{mm})$

Calculation and Evaluation of Processing Capacity. After the establishment of the model, the milling cutter processing capacity factors can significantly obtained. In order to further evaluate the machining ability of milling cutter, a method combining AHP and fuzzy mathematics is proposed. With this method, the processing ability of the milling cutter is simplified, and the various influencing factors of the milling cutter are combined, and the evaluation results are given. First, the multiple factors that affect the processing ability are classified and stratified, it also means establishment of the structure level model. Second, according to the preference of each layer to use the 1-9 scale method quantify those factors, the quantized values are compared and the weights are calculated [5-7], and their weights are obtained. Using fuzzy mathematics quantify those factors which are hard to quantify and various uncertain to obtain all kinds of uncertain factors by fuzzy mapping or its membership degree [8]. Final, the comprehensive evaluation result is obtained by calculating the membership degree and weight. The corresponding flow chart is shown in Fig. 2 


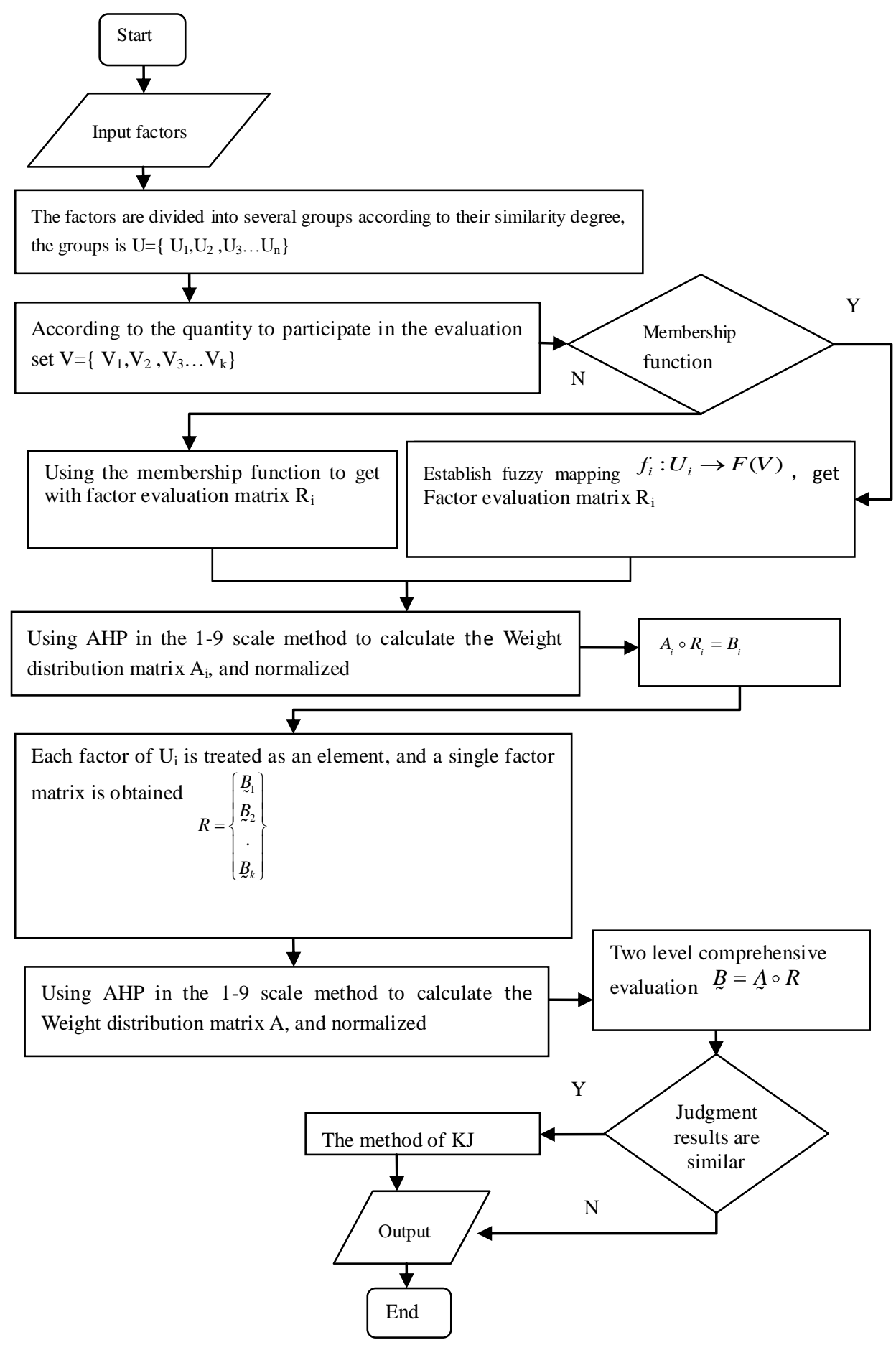

Figure 2. Evaluation Model Flow Chart

According to the flow chart to complete the processing capacity of the milling cutter evaluation, the final result is the form of comprehensive evaluation matrix, when the judgment matrix in the presence of two or more than two similar quantitative, and difficult to determine its processing capacity of the level, KJ method was used to further treatment [10]. That is, when the final evaluation appears when there are two kinds of tool weight factors are equivalent, the method can be used. After the end of the comprehensive evaluation matrix can be judged according to the weight of each parameter, the higher weight means strong processing capacity. 


\section{Comparative Analysis}

There are a variety of models to choose from in the past evaluation system, but in the selection process, you need to clear the strengths and weaknesses of each model, aware of the advantages of the model fully can better follow-up expansion and understanding Lay the foundation. Therefore, in order to fully understand the use of model and applicable scope, analysis of processing capacity to evaluate some models. The analysis and comparison are shown in Table 1

Table 1 Comparison Model

\begin{tabular}{|c|c|c|c|c|}
\hline Model Name & $\begin{array}{c}\text { Scope of } \\
\text { application }\end{array}$ & Key Technologies & Advantages & Shortcomings \\
\hline $\mathrm{STEP}^{[1]}$ & $\begin{array}{l}\text { Mostly for } \\
\text { software system } \\
\text { development }\end{array}$ & Group Technology & $\begin{array}{l}\text { Compatibility, long life } \\
\text { cycle and scalability. To } \\
\text { achieve the optimal } \\
\text { combination of resources } \\
\text { and information } \\
\text { seamlessly. }\end{array}$ & $\begin{array}{l}\text { The actual operation } \\
\text { time-consuming and labor } \\
\text {-intensive, no complete } \\
\text { standard for reference at } \\
\text { this stage, difficult to } \\
\text { evaluate. }\end{array}$ \\
\hline $\begin{array}{l}\text { Maturity } \\
\text { model }^{[11]}\end{array}$ & $\begin{array}{l}\text { The amount of } \\
\text { change is } \\
\text { introduced in } \\
\text { increments. } \\
\text { Mostly for the } \\
\text { software } \\
\text { industry. }\end{array}$ & $\begin{array}{l}\text { A standard which } \\
\text { descript the various } \\
\text { stages of development } \\
\text { in the definition, } \\
\text { implementation, } \\
\text { measurement, control } \\
\text { and improvement of a } \\
\text { factor }\end{array}$ & $\begin{array}{l}\text { The organization uses } \\
\text { statistics and process } \\
\text { control techniques as a } \\
\text { guide and has feedback } \\
\text { mechanism. }\end{array}$ & $\begin{array}{l}\text { Unable to deal with the } \\
\text { factors of increment }\end{array}$ \\
\hline $\begin{array}{l}\text { Based on } \\
\text { AHP and } \\
\text { Fuzzy } \\
\text { Mathematics } \\
\text { Modeling }\end{array}$ & $\begin{array}{l}\text { Evaluation of } \\
\text { single tool for } \\
\text { machining } \\
\text { types, The } \\
\text { preliminary } \\
\text { choosing } \\
\text { according to this } \\
\text { model. }\end{array}$ & $\begin{array}{c}\text { AHP, } \\
\text { fuzzy mathematics } \\
\text { and relational algebra. }\end{array}$ & $\begin{array}{l}\text { You can assess more than } \\
\text { ever before the factors, do } \\
\text { not rigidly adhere to the } \\
\text { few factors that improve } \\
\text { the ability to assess the } \\
\text { accuracy of tooling. }\end{array}$ & $\begin{array}{l}\text { The membership function } \\
\text { is difficult to obtain, and } \\
\text { some special factors need } \\
\text { to refer the calculation } \\
\text { formula, which increases } \\
\text { the complexity of the } \\
\text { evaluation process and the } \\
\text { calculation. }\end{array}$ \\
\hline
\end{tabular}

From the comparison of the above models, it can be clearly seen that compared with other models, the process capability modeling based on AHP and fuzzy mathematics is more specific and accurate than other models in the evaluation process. The milling cutter's processing capacity of the impact of many factors, and fuzzy comprehensive evaluation itself on a variety of factors affecting the comprehensive evaluation of things is very effective. There are many affecting the processing capacity factors of milling cutter, and fuzzy comprehensive evaluation of the various factors affecting the comprehensive evaluation of things is very effective. Compared with the past fuzzy evaluation, the new evaluation method adopted has added some new factors, ideas and methods of the solution in the final evaluation of the milling cutters, and improve the credibility of the cutting tool evaluation.

\section{Conclusions and Prospects}

This paper describes and studies the processing capacity of the cutter, using fuzzy evaluation and AHP to evaluate the machining ability, which makes up for the existing evaluation system is only concerned about the tool for processing quality evaluation of parts of the study, while ignoring some of the parameters of the tool itself. Through the processing ability of the milling cutter's reliable and effective evaluation, it's helpful to choose the cutting tool for the enterprise or the craft designer and provide more reliable support for the development of process cards.

In this paper, partial reference factor selected as a parameters, so its evaluation isn't very perfect. In the following research, it is possible to introduce more factors that affect the processing ability of 
the milling cutter, and the correlation between these factors is analyzed. So that the processing capacity of the cutter to judge more specific and reliable.

\section{Acknowledgments}

This paper is supported by both Shaanxi Provincial Department of Education special research projects under Granted NO.16JK1388 and Xi'an Technological University president fund under Granted NO.XAGDXJJ15004. The authors hereby thank both Education Department of Shaanxi Province and Xi'an Technological University president fund for the financial aids.

\section{References}

[1] Y.Y. Song, X.P. Chu and F.Z. Cai Research on Manufacturing Resource Capability Modeling and Its Application Based on Step[J].CIMS. 1999.04

[2] J. Wang and W.Z. Ding. Machining Capability of CNC Machine Tools Based on Fuzzy Comprehensive Evaluation [J].Modular Machine Tool \& Automatic Manufacturing Technique. 2014.11

[3] Y.Y. Xiao, B.H. Li, X.D. Chai and J. Gong. Research on the Formalization Description method of Manufacturing Capability Service in Cloud Manufacturing. Journal of System Simulation.2015.09:2096-2107.

[4] Q.Q. Zhu and P.J. Jiang. Formal Model of Machining Capacity for a Marching System [J].Journal of Xi' an JIAO TONG University.2011.11

[5] Jailor Rafael Canutillo; Marco A Bushtit; Eduardo A. Portola Santos; Eduardo R. Lourdes. Hybrid Control Architecture Applied to Flexible Manufacturing Systems . IFAC Proceedings Volumes. 2008

[6] K.K. Bi, Z.W. Niu, N. Zhao, W. Peng and K.N. Tong. Algorithm of Manufacturing Demands and Resource Matching Under Piece Production Model Based on Analytic Hierarchy Process (AHP) and IFS [J].2015.5

[7] Grace K.L.Lee and Edwin H.W.Chan. The Analytic Hierarchy Process (AHP) Approach for Assessment of Urborn proposals. Soc Indic Res. 89(2008), 155-168.

[8] Lowen R.1988.Mtathematics and fuzziness. Fuzzy set and Systerms, 27(1):1-3

[9] F. Zhou, J. Zhou, Y.W. He and D.Y. Song. Research on Usability of Human-machine User Interface Based on KJ Method and ANP Method [J].Science Technology and Engineering.2015.2:241-245.

[10]D.C. Zhan, Z. Cheng, X.B. Zhao, L.S. Nie and X.F. Xu. Manufacturing Service and Its Maturing Model [J]. Computer Integrated Manufacturing Systems.2012.7:1584-1594. 